\title{
Editorial
}

\section{Antibiotic for Future: Disarm Bacteria, Don't Kill!!}

\author{
Received: December 23, 2018 Accepted: December 29, 2018 \\ doi: https://doi.org/10.3329/jemc.v9i1.39897
}

The global emergence of antimicrobial resistance has become a pre-eminent concern in medical and public health. ${ }^{1}$ Resistance in bacterial pathogen is an inevitable consequence of antibiotic use. Despite the repeated warning negligent antibiotic use and poor infection control practice have led to continuing development of extensive resistance problem. ${ }^{2}$

Increasing antimicrobial resistance and multiple drug resistance have resulted in increasing difficulties in the treatment of bacterial infections. Resistance leads to inappropriate empirical therapy, delay in starting effective treatment, use of less effective, more toxic and more expensive drugs, treatment failure, prolonged or additional hospitalization, increased cost of care and increased mortality. ${ }^{2}$

Multiple factors contribute to resistance including overuse, infection in immune-compromized patients and increased use of indwelling medical devices which provide a fostering environment. ${ }^{3}$ It has recently been suggested that biofilm-resident bacteria 'communicate' by a process termed quorum sensing and this contributes to their competitive advantages and enhanced antibiotic resistance. ${ }^{4}$

Many bacterial species are now known to form biofilms. Gram-positive and Gram-negative bacteria and yeasts can coexist within the same biofilm. ${ }^{3}$ Biofilm is described as "an assemblage of microbial cells that is irreversibly associated (not removed by gentle rinsing) with a surface and enclosed in a matrix of primarily polysaccharide material". ${ }^{3}$ Biofilm formation is considered as the major contributor to the bacterial virulence. ${ }^{5}$

Despite increasing antimicrobial resistance and multiple drug resistance in clinical isolate, there are few novel antimicrobial agents in development. Scientists are trying different approaches to kill bacteria. They try to add 'silver' to boost up the antibiotic power, so that it can penetrate bacteria easily. Another approach is if an antibiotic selectively breaks down in the gut, it can be taken in larger doses. The drug could continue to circulate in the blood while minimizing adverse effects. Scientists are also trying to mapping the bacterial genome, so that effective antibiotic can be invented. In this perspective, the bacterial communication (Quorum sensing) offers a potential target for designing of novel antimicrobial drugs. Here researchers are trying to confuse the bacteria by stopping them to release toxins or by suppressing virulence. This would remove the ability of pathogens to cause infection.

Quorum sensing has recently discovered a chemical communication system among bacteria (both Grampositive and Gram-negative) ${ }^{4}$ It is a form of bacterial communication that helps regulating group behavior. Bacteria release chemical substances called autoinducers into their surroundings. As the population density increases, so does auto-inducer concentration. When the population density is sufficiently high (i.e. a quorum is achieved), auto-inducer concentrations become high enough to bind to receptors on/within nearby bacteria. The signal is then transduced into an intracellular biochemical signal or altered gene expression in the target bacteria. ${ }^{4}$

\section{Mahmuda Begum}

Professor, Department of Pharmacology and Therapeutics Enam Medical College, Savar, Dhaka

Email: mahmudarini62@gmail.com

\section{References}

1. Bush K. Why it is important to continue antibacterial drug discovery? ASM news - American Society for Microbiology 2004; 70(6): 282-287.

2. French GL. The continuing crisis in antibiotic resistance. International Journal of Antimicrobial Agents 2010; 36(3): S3-S7.

3. Donlan RM. Biofilms: microbial life on surfaces. Emerg Infec Dis 2002; 8: 881- 888.

4. Raffa BR, Lannuzzo JR, Levine DR, Saeid KK, Schwartz RC, Sucic NT et al. Bacterial communication ('quorum sensing') via ligands and receptors: a novel pharmacologic target for the design of antibiotic drugs. The journal of Pharmacology and Experimental Therapeutics 2005; 312(2): 417-423.

5. Vuong C, Gerke C, Somerville GA, Fischer ER, Otto M. Quorum sensing control of biofilm factors in Staphylococcus epidermidis. J Infect Dis 2003; 188: $706-718$. 